\title{
Seed development and inheritance studies in apomictic maize-Tripsacum hybrids reveal barriers for the transfer of apomixis into sexual crops
}

\author{
OLIVIER LEBLANC*,1, DANIEL GRIMANELLI ${ }^{1}$, MARTHA HERNANDEZ-RODRIGUEZ², PABLO A. GALINDO², \\ ANA M. SORIANO-MARTINEZ ${ }^{2, \# ~ a n d ~ E N R I C O ~ P E R O T T I ', 3 ~}$ \\ ${ }^{1}$ Laboratoire Génome et Développement des Plantes (LGDP), UMR 5096 IRD-CNRS-Université de Perpignan, Montpellier, France, \\ ${ }^{2}$ International Maize and Wheat Improvement Center, Texcoco 56130, Mexico and \\ ${ }^{3}$ Plant Cell Biology Group, Australian National University, Canberra ACT, Australia
}

\begin{abstract}
Apomixis in plants covers a variety of cloning systems through seeds of great potential for plant breeding. Among long-standing approaches for crop improvement is the attempt to exploit wild relatives as natural, vast reservoirs for novel genetic variation. With regard to apomixis, maize possesses an apomictic wild relative, Tripsacum, which we used to produce advanced maize-Tripsacum hybrid generations. However, introgression of apomixis in maize has failed so far. In order to understand the how's and why's, we undertook characterization of seed development and inheritance studies in these materials. We show that apomictic seeds suffer from epigenetic loads. Both seed tissues, the endosperm and the embryo, displayed developmental defects resulting from imbalanced parental genomic contributions and aberrant methylation patterns, respectively. Progeny characterization of several maize-Tripsacum hybrid generations allowed significant progress toward the unraveling of the genetics of apomixis. First, chromosome deletion mapping showed that expression of apomixis requires one single Tripsacum chromosome. However, inheritance studies revealed that female gametes inheriting this segment were unequivalent carriers depending on their origin: unreduced gametes transmit a functional segment, whereas progeny derived from reduced ones reproduced sexually. Finally, chromosomal or genomic dosage variation barely affected the apomictic phenotype suggesting no dependency for ploidy in these materials. We conclude that epigenetic information imposes constraints for apomictic seed development and seems pivotal for transgenerational propagation of apomixis. The nature of the triggering mechanisms remains unknown as-yet, but it certainly explains the modest success relative to the development of apomictic maize thus far.
\end{abstract}

KEY WORDS: apomixis, seed development, maize, epigenetics, interspecific hybrid

\section{Introduction}

The Tripsacum genus comprises wild relatives of maize (Zea mays L.) widely distributed across the American continent and highly variable in many aspects (Berthaud et al., 1997, Randolph, 1970). Efforts towards allele mining out of this diverse, genetic reservoir have been limited so far (for instance, resistance to Puccinia sorghi; Bergquist, 1981). One notable exception concerns apomixis or the formation of maternal embryos within seeds
(Koltunow, 1993, Nogler, 1984), a reproductive behavior of great potential for agriculture and plant breeding (Spillane et al., 2004).

Apomixis in higher plants is achieved through a number of routes, most of which still lack detailed characterization. Apomictic developments have been categorized into adventitious embryony and gametophytic apomixis depending on the cell type

Abbreviations used in this paper:AFLP, amplified fragment length polymorphism; RFLP, restriction fragment length polymorphism.

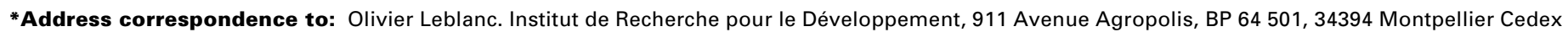
05, France. Fax: +33-04-6741-6181. e-mail: olivier.leblanc@ird.fr Lab web address: http://lgdp.univ-perp.fr

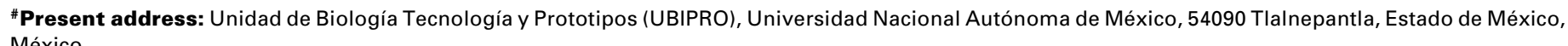
México
} 
that gives rise to maternal embryos, i.e. somatic cells within the ovule and parthenogenetical egg cells within unreduced megagametophytes, respectively (Gustafsson, 1946, Koltunow, 1993, Nogler, 1984). Recent works in species reproducing through distinct pathways, i.e. Hieracium subgenus pilosella, Poa, and Tripsacum, suggest that gametophytic apomixis (referred to as apomixis herein) relies upon either spatial or temporal

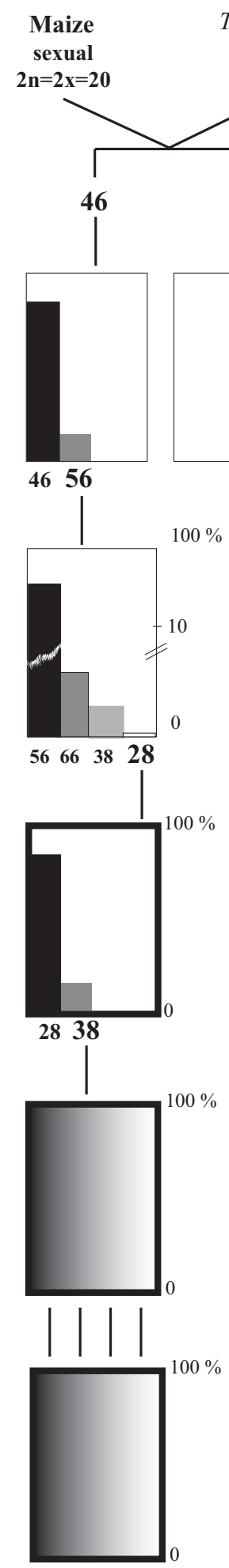

Fig. 1. Pedigree of 38-chromosome maizeTripsacum hybrids $(2 \mathrm{n}=\mathbf{2 0} \mathrm{M}+18 \mathrm{Td})$ and derivatives. Boxes display progeny sorting after data compilation from previous reports (Grimanelli et al., 1998, Leblanc, 1995, Leblanc et al., 1996) and unpublished results (O. Leblanc). Materials used in this work are from bolded boxes. Boxes with gradient color background represent undetermined progeny prior to this work. M: maize. Td: Tripsacum dactyloides. misexpression of genes acting during female sexual reproduction (Albertini et al., 2004, Grimanelli et al., 2003, Tucker et al., 2003). However, although candidate genes showing differences in spatial and temporal expression patterns between apomicts and their sexual counterparts have been identified, both their involvement in the control of apomixis and function remain largely speculative (Ozias-Akins, 2006). Inheritance studies have provided a relatively simple view for the genetics of apomixis, which was reported to depend on a few dominant genes in most species investigated (Asker and Jerling, 1992, Ozias-Akins and van Dijk, 2007). Challenging this, further molecular mapping and cytogenetic characterization of the chromosomal region(s) linked to the trait in several species have unveiled attributes frequently associated with complex loci, such as lack of recombination, trans-acting mechanism for gamete elimination, heterochromatinization and DNA rearrangements (Ozias-Akins and van Dijk, 2007). To date, the genetic control of apomixis remains confuse, as no apomictic locus has been molecularly resolved. Alike, whether the complex nature of apomictic loci or polyploidy, a usual feature of apomictic genomes, take part in the control of the trait is unknown. Fueling the debate, functional roles for polyploidy have been hypothesized, including epigenetic gene deregulation (Koltunow and Grossniklaus, 2003), ploidy-dependent gene expression (Cervigni et al., 2008, Quarin et al., 2001), or ectopic gene expression resulting from genome asynchrony (Carman, 1997). On the other hand, these complexities were proposed to have evolved once apomictic reproduction established, thus they may be secondary with regards to its genetic control (Ozias-Akins and van Dijk, 2007).

Within the Maydae tribe, apomixis occurs in Tripsacum only (Brown and Emery, 1958), making the genus a prime candidate to elaborate strategies for its transfer to maize either directly through backcrossing or by genetic engineering. Tripsacum species typically compose an agamic complex (after Babcock and Stebbins, 1938) wherein diploid individuals $(x=18,2 n=2 x=36)$ are sexual and polyploid individuals $(2 n=3 x$ to $6 x$ ) reproduce apomictically. Apomixis is gametophytic of the diplosporous type (Farquharson, 1955, Leblanc et al., 1995b): functional, unreduced megaspores form after omission, or early termination, of meiosis in megaspore mother cells (Grimanelli et al., 2003). Further differentiation into megagametophytes resembles that of the Polygonum type found in sexual species, but cells contain nuclei of maternal genetic makeup. Activation of unreduced egg cells through unknown developmental alterations in female gametogenesis induces embryogenesis in absence of fertilization (Bantin et al., 2001, Farquharson, 1955) but the developmental course of maternal embryos stops after a few rounds of mitotic divisions resulting in quiescent proembryos within unfertilized megagametophytes (Grimanelli et al., 2003). Pollination, followed by the delivery of two sperm cells into the mature megagametophyte and by the fertilization of the central cell only, is required for seed development. As in many other apomicts, apomixis in Tripsacum plants is facultative as reproductive behaviors that allow genetic variation have been preserved through evolution. The most documented ones result from partial or complete restoration of sexual programs (Asker and Jerling, 1992, Bicknell and Koltunow, 2004), but other mechanisms such as incomplete nucleus restitution during meiosis abortion, mitotic and meiotic non-disjunction, somatic recombination, and gene 

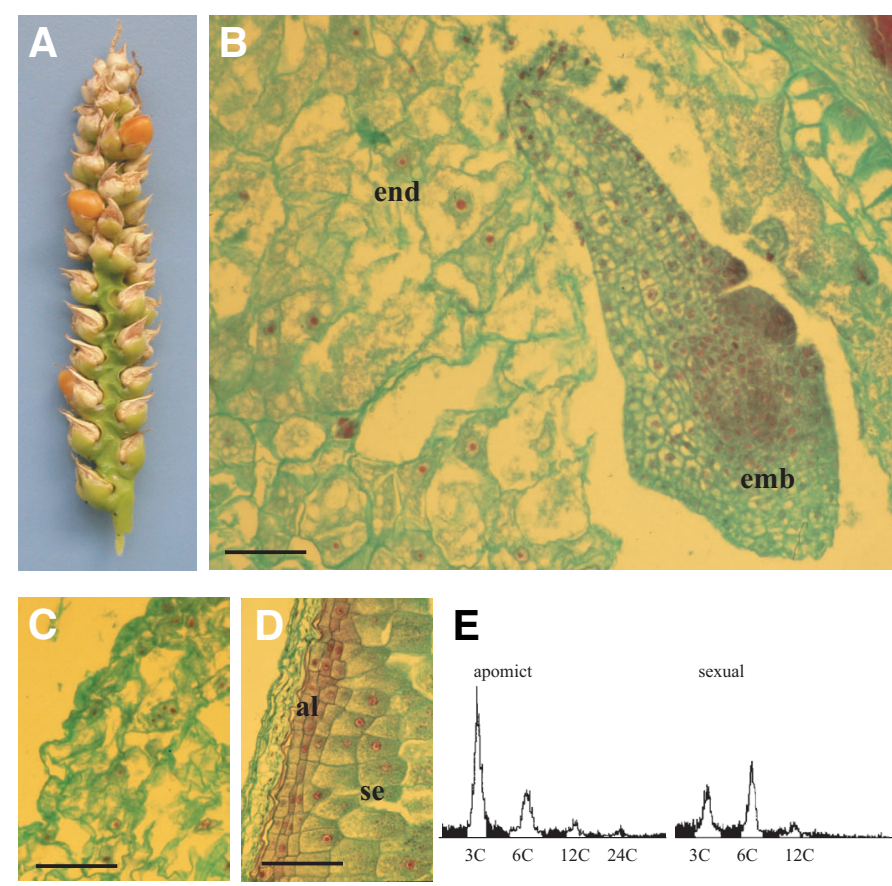

mutation have been reported as well (Hair, 1956, Noyes, 2005, Richards, 1996).

Since maize and Tripsacum were first hybridized in the early 30's (Mangelsdorf and Reeves, 1931), pathways for introgressing Tripsacum genetic material into the crop have been extensively scrutinized (Harlan et al., 1970, Harlan and DeWet, 1977). Nevertheless, in spite of several decades of efforts (Kindiger and Sokolov, 1997, Leblanc, 1995, Leblanc et al., 1996, Petrov et al., 1984), no maize germplasm expressing some level of apomixis has been recovered yet. Conventional backcrossing at CIMMYT using a $T$. dactyloides apomictic donor and maize yielded facultative apomictic hybrids possessing two maize (M) genomes and one genome from $T$. dactyloides (Td) (i.e., $2 n=38=20 M+18 T d$ ) (Leblanc et al., 1996). Here, we report on both female reproductive behavior and genomic characterization in these materials and derivative generations (Figure 1, Table 1). Our observations shed light onto critical obstacles, some of them likely of epigenetic nature, such as developmental abnormalities in apomictic seeds, methylation pattern differences following apomictic reproduction, and unexpected behavior of the chromosomal region that governs apomixis. Collectively, they provide an explanation for the modest success of transfer attempts to date.

\section{Results}

\section{Seed developmental abnormalities in maize-Tripsacum and Tripsacum apomicts}

Seed development in maize-Tripsacum individuals with 38 chromosomes $(2 n=20 M+18 T d)$ hand pollinated using diploid maize individuals initiated for $36 \pm 9 \%$ of the flowers (mean $\pm S D$; $>2000$ flowers from 3 different cycles, 10 plants per cycle, 2 inflorescences per plant). Mature kernels were highly variable with regard to endosperm formation (Figure 2A), however with a strong trend toward defective development (65 to $80 \%$ ). By contrast, $84 \pm 9 \%$ kernels (mean $\pm S D, N=744$ ) contained a
Fig. 2. Seed development in $\mathbf{2 n = 3 8}$ maize-Tripsacum (38C clone) and Tripsacum dactyloides apomicts. (A) Typical inflorescence of $38 \mathrm{C}$ clone pollinated using diploid maize. (B) Section in mature kernel of $38 \mathrm{C}$ showing a normal-looking embryo (emb) but surrounded by atypical endosperm cells (end). (C) Peripheral section of 38C endosperm with altered cell differentiation. (D) Peripheral section of normal endosperm from a sexual Tripsacum dactyloides strain: (al) aleurone layer cells, and (se) starchy endosperm cells. (E) Cell cycle analysis in endosperms from apomictic and sexual tetraploid Tripsacum strains. Bars, $300 \mu \mathrm{m}$.

morphologically normal embryo (Figure $2 \mathrm{~B}$ ). This suggests that endosperm collapsing occurred after cellularization, a critical step whereby apomictic proembryos resume development (Grimanelli et al., 2003). Unfavorable allelic interactions might have promoted endosperm failure, but a more plausible explanation is that development primarily suffered from maternal genomic excess. In endosperms from $2 n=38$ individuals pollinated with diploid maize, mother plants typically contributed six genomes (4M and 2Td) for a single paternal genome $(1 \mathrm{M})$. This corresponds to a strong distortion of the typical 2 maternal to 1 paternal genomic ratio $(2 \mathrm{~m}$ : $1 \mathrm{p})$ required for normal seed development in many Angiosperms, including maize (Lin, 1984, Nishiyama and Inomata, 1966) and Tripsacum, as indicated by flow cytometrical analyses in normal and imbalanced endosperms. As shown in Figure 2E, endoreduplication in endosperms derived from $4 \mathrm{x}$ apomicts crossed with $4 \mathrm{x}$ male progenitors $(2 \mathrm{n}=10 \mathrm{x}, 8 \mathrm{~m}$ : $2 \mathrm{p})$ occurred precociously compared to $6 x$ normal endosperms $(4 \mathrm{~m}: 2 \mathrm{p} ; 4 \mathrm{x}$ sexuals $X 4 x$ progenitors), a difference in cell cycle progression already reported in maize as a mark for maternal excess (Leblanc et al., 2002). Dosage effects incidence in the endosperm of $2 n=38$ apomicts was corroborated by observations made from sectioned developing kernels. Cell growth was affected similarly to that of maize endosperms suffering from maternal genomic excess (Cooper, 1951): i. e., enlarged central cells, undifferentiated basal cell layer, and poor subepidermal differentiation (compare Figure $2 \mathrm{C}$ and 2D). Nevertheless, deleterious effects appeared less

TABLE 1

\section{LIST OF THE TRIPSACUM AND MAIZE STOCKS USED AND OBTAINED FROM CIMMYT GERMPLASM BANK}

\begin{tabular}{ll} 
T. dactyloides ecotypes & Improved maize populations \\
\hline $11-36$ & BS13 (S) C8 \\
$61-664$ & BSSS (R) C13 \\
$65-1234$ & BS10 (FR) C11 \\
$112-1327$ & BS26 (S) C13 \\
$112-1328$ & BSCB1 (R) C13 \\
Maize lines (CMLs) & BS11 (FR) C11 \\
\hline CML62 ${ }^{(2)}$ & POB.21C6 $\times$ BS10 (FR) C11 \\
CML78 & POB.43C10 $\times$ BS10 (FR) C11 \\
CML135 ${ }^{(1,2)}$ & POB.24C9 $\times$ BS10 (FR) C11 \\
CML139 ${ }^{(1)}$ & POB.27C10 BS26 (S) C3 \\
CML204 & POB.25C4 $\times$ BSCB1(R) C13 \\
CML216 & POB.27C10 BSCB1(R) C13 \\
CML258 & POB.21C6 \\
CML341 & POB.43C10 \\
CML346 & POB.24C9 \\
CML408, & POB.25C4 \\
CML413 & POB.32C6 \\
CML416 & POB.27C10 \\
\hline
\end{tabular}

(1) and (2): lines used to derive $\mathrm{H} 1$ and $\mathrm{H} 3$ maize hybrids, respectively. 


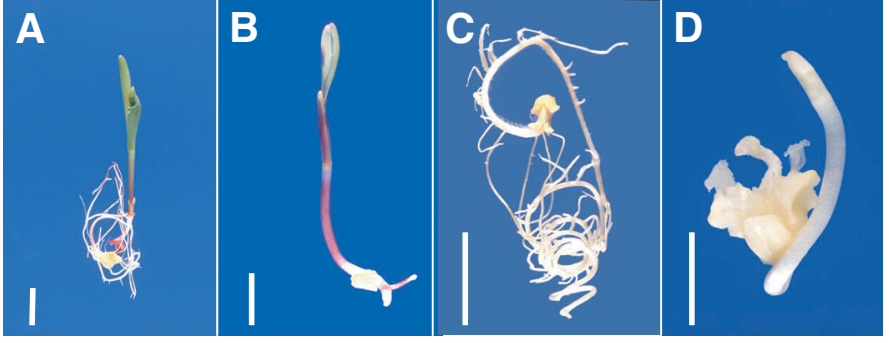

E

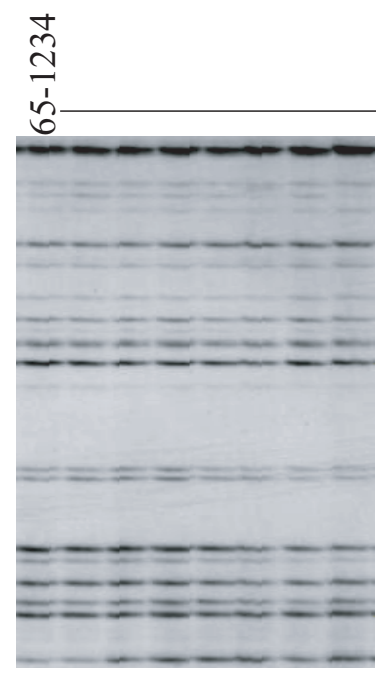

EcoRI/MseI digests

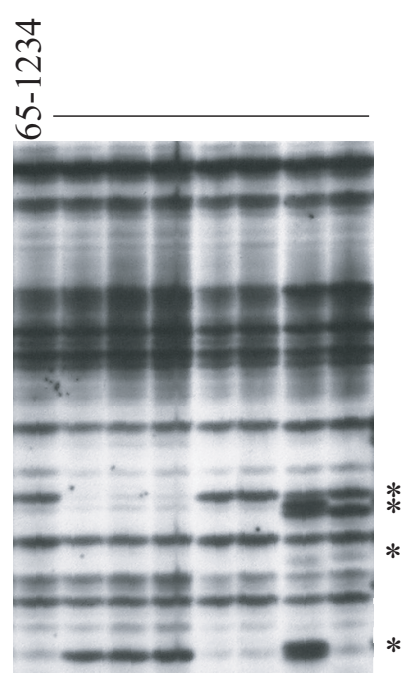

EcoRI/HpaII digests

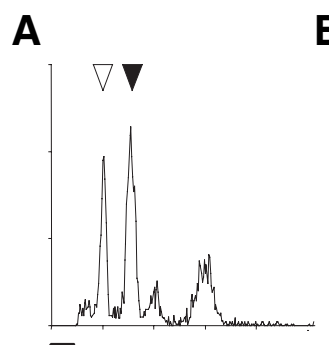

B

D

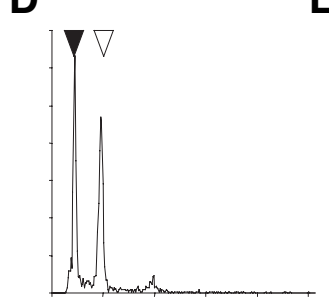

$\mathbf{F}$

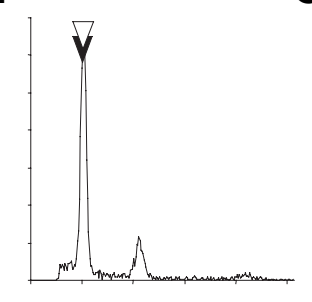

-

E

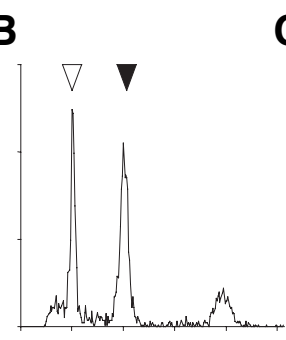

C
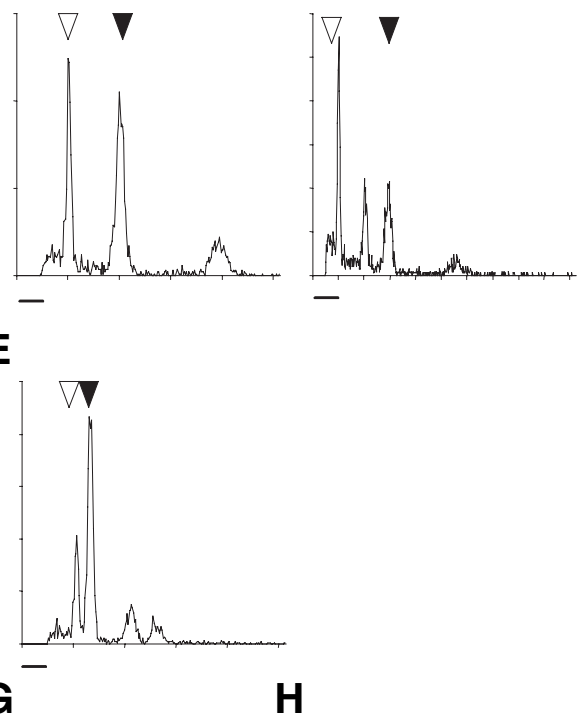

H

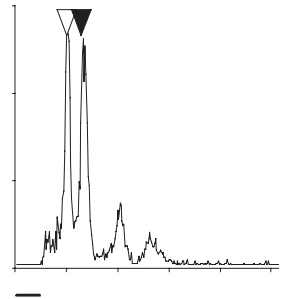

Fig. 3 (Left). Maternal embryo defects in maize-Tripsacum and Tripsacum apomicts. (A-D) Germination of maternal seedlings from seeds from maize-Tripsacum apomict 38C showing normal (A) and aberrant (B-D) developments. Bars, $1 \mathrm{~cm}$. (E) Genomic cloning (EcoRl/ Mse/ digests) and detection of methylation-associated polymorphisms (EcoRI/Hpall digests) through AFLP fingerprinting in maternal progenies of 65-1234, a tetraploid, apomictic T. dactyloides ecotype. Asterisks indicate differentially methylated restriction sites.

Fig. 4 (Right). Progeny sorting of apomictic clone 38C after DNA content analyses in young seedlings. (A) Maternal clone with $2 n=38$. (B,C) Off type progeny with higher DNA contents than that of maternal clones: $2 n=48$ (B) and $2 n=76$ (C). (D-H) Off type progeny with lower DNA contents than that of maternal clones: $2 n=10$ (D), $2 n=28(\mathbf{E}), 2 n=20$ (F), $2 n=22$ (G), $2 n=27$ (H). Open and dark triangles indicate $2 C$ peaks produced by nuclei isolated from CML62, the diploid maize reference, and from the sample, respectively. Chromosome numbers were determined by root tip counts. Bar, 50-channel intensity.

critical in our materials than those reported for maize in which $<1 \%$ of the $4 x \times 2 x$ kernels produce an endosperm (Cooper, 1951, Leblanc et al., 2002). Developmental adaptations that ultimately restore the endosperm balance requirement are frequent in apomicts (Grimanelli et al., 1997, Grossniklaus et al., 2001, Nogler, 1984). Among these, the union of polar nuclei with two sperm nuclei could have contributed to dosage effect alleviation in $38 \mathrm{C} \times 2 \times$ endosperms. To further investigate the importance of such fertilization events in seed development of apomicts, we directly estimated DNA contents in growing endosperms from normally developed kernels obtained 15 days after pollination with diploid maize $(\mathrm{H} 3)$. Flow cytometry analyses indicated that $1 \mathrm{x}$ paternal contribution (fertilization by a single sperm cell) was predominant $(80 \%, n=86)$. Therefore, fertilization of the central cell by two sperm cells unlikely served as a critical factor to mitigate dosage effects in endosperms of $2 n=38$ apomicts.

Defects were also common during embryo germination. Despite the use of an in vitro procedure, germination of kernels with developed endosperm usually expanded over several weeks and produced less than $60 \%$ viable seedlings (Table 2). Low seed fertility resulted from lack of germination but also from developmental alterations, including early developmental arrest, undifferentiated growth, and differentiation failure of shoot or roots (Figures 3A to 3D). Polyembryonic kernels were frequent (Table 2), a trend that is usually associated to apomictic developments (Hanna and Bashaw, 1987) and for which we have provided recently a detailed characterization in Tripsacum and maize-Tripsacum hybrids (Grimanelli et al., 2003). Finally, although development initiated to a lesser extent than in embryos accompanied by an endosperm, embryos dissected from defective kernels and cultured on a hormone-free medium exhibited similar defective developmental behaviors (data not shown).

In cloning of both animals and plants, analogous developmental defects have been correlated to inaccurate DNA methylation patterns for key developmental gene (Kaeppler et al., 2000, Reik and Dean, 2001, Rideout et al., 2001). To investigate whether this 
phenomenon perturbs embryo development in apomicts, we studied progeny from five apomictic Tripsacum dactyloides individuals. First, similarly to that observed in maize-Tripsacum hybrids, germination rates of normal seeds were low (33 to 70\%) and a significant proportion (4 to $55 \%$ ) of the germinating seeds were affected in development (Table 3). Altogether, viable adult plants were recovered for only $25 \%$ of the seeds. Late-occurring defects were also observed in adult plants, including sterility and delayed flowering time (respectively, $8 \%$ and $4 \%, n=70$ ). We further performed a genome-wide characterization of DNA methylation for each progeny. As control experiments, we used two populations representing non-apomictically derived, but genetic replica, of the mother plant; the first one $(n=10)$ consisted of cuttings of a single apomictic genotype, 65-1234 while the second one $(n=12)$ was generated by selfing CML216, a maize homozygous line. We first verified that the three procedures we used reproduced faithfully mother plant genotypes by generating AFLP fingerprints from DNAs cleaved using EcoRl and-Msel, two methyl-insensitive restriction enzymes. All loci scored $(n>250)$ were strictly monomorphic in all cases studied (mother plant vs. progeny/replica, amongst progeny; Figure 3E). Then, we assessed methylation status of CCGG sites using a modified AFLP procedure using EcoRl/Mspl or EcoRl/Hpall digests as preamplification DNA templates (Cervera et al., 2002). For both EcoRl/Hpall and EcoRl/Mspl digests, we observed identical fingerprints among replica used for control experiments, indicating conservation of genome methylation patterns (data not shown). By contrast, patterns of digestion among clonal individuals derived apomictically showed methylation-sensitive polymorphisms: firstly, pairwise comparisons of methylation patterns revealed that a significant fraction of the fragments detected using EcoR1/

\section{TABLE 2}

PROGENY CLASSES FROM 38C APOMICTS POLLINATED USING DIPLOID MAIZE AS DETERMINED BY DNA CONTENT ANALYSES

\begin{tabular}{lccccccc} 
Male & $\mathrm{Nt}$ & $\mathrm{Ge}(\%)$ & $\mathrm{Me}(\%)$ & $\mathrm{Npr}$ & Mp (\%) & Inc (\%) & Dec (\%) \\
\hline $\mathrm{H}^{(1)}$ & 7,393 & 54 & 17.3 & 4,691 & 93.7 & 6.1 & 0.2 \\
$\mathrm{H}^{(2)}$ & 10,206 & 49.5 & 13.0 & 5,740 & 88.2 & 11.5 & 0.3 \\
$\mathrm{All}$ & - & - & - & $>100,000$ & 91.0 & 8.8 & 0.2 \\
\hline
\end{tabular}

$\mathrm{Nt}$ : total number of kernels; Ge: kernels that produced viable seedlings; Me: multiple embryos; Npr: number of viable progeny recovered; Mp: maternal progeny (same DNA content as mother plants); Inc: off type progeny showing increase in DNA content; Dec: off type progeny showing decrease in DNA content. (1) 2001 winter cycle; (2) 2002 summer cycle

\section{TABLE 3}

\section{DEVELOPMENTAL DEFECTS IN APOMICTIC TRIPSACUM DACTYLOIDES PROGENIES}

\begin{tabular}{lcccc} 
Accession number & $\begin{array}{c}\text { Germinating } \\
\text { seeds }(\%)\end{array}$ & $\begin{array}{c}\text { Early arrest } \\
(\%)^{\mathbf{a}}\end{array}$ & $\begin{array}{c}\text { Undifferentiated } \\
{\text { growth }(\%)^{\mathbf{a}}}^{\mathbf{a}}\end{array}$ & $\begin{array}{c}\text { Viable adult } \\
\text { plant }(\%)\end{array}$ \\
\hline $65-1234(\mathrm{n}=145)$ & 35 & 33 & 22 & 16 \\
$11-36(\mathrm{n}=34)$ & 68 & 0 & 4 & 65 \\
$61-664(\mathrm{n}=22)$ & 73 & 19 & 31 & 36 \\
$122-1327(\mathrm{n}=42)$ & 33 & 7 & 14 & 26 \\
$112-1338(\mathrm{n}=38)$ & 32 & 17 & 33 & 16 \\
Total $(\mathrm{n}=281)$ & 41 & 20 & 20 & 25 \\
\hline
\end{tabular}

a values shown were determined for germinated seeds
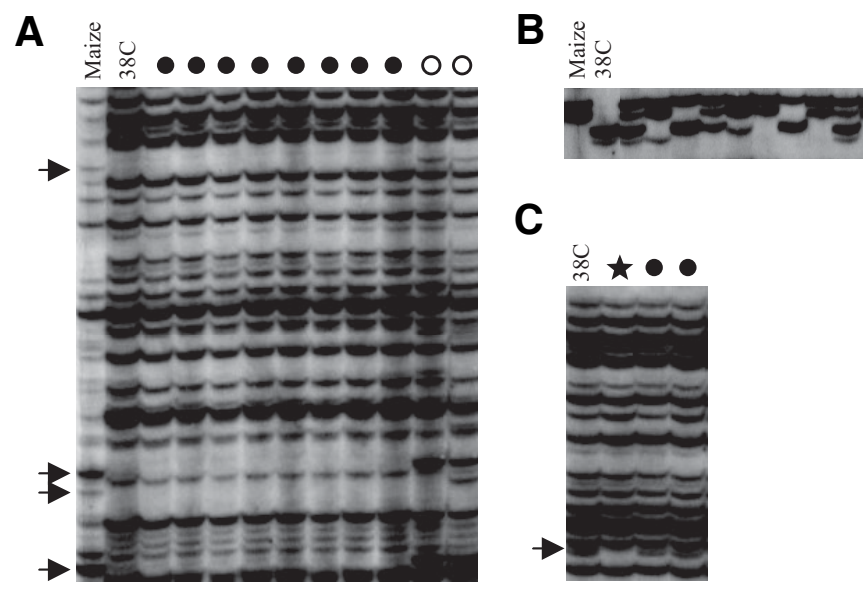

Fig. 5. AFLP genotyping of progeny from maize-Tripsacum apomictic clone 38C. (A) Derivatives through unreduced female gametes. Dark and open circles respectively indicate maternal progeny or off type progeny after fertilization (genomic accumulation, open circles). Arrows show maize fragments specific to the male progenitor. (B) Sexual derivatives. (C) Sporadic chromosome loss in one individual derived from unreduced, parthenogenetical female gametes (star). The arrow indicates one missing fragment.

Hpall digests (5.8\%; $\mathrm{n}>250$ ) were polymorphic (Figure 3E) whilst they appeared monomorphic using EcoR1/Msp1 digests. Furthermore, we also detected polymorphisms for $2.4 \%$ of the fragments amplified from EcoR1/Msp1 digests. We thus conclude that apomictic clones differed for methylation patterns within CCGG regions despite genomic identity. These results suggest that inaccurate erasing, maintenance or establishment of DNA methylation might occur during apomictic reproduction and that, as observed in animals (Dean et al., 2001), this could explain the defects noted in maternal embryos.

\section{Reproduction in 38-chromosome apomictic clones can oc- cur through a variety of mechanisms}

Variation in the reproductive behavior within a single individual is common in both natural and artificial apomicts (Koltunow et al., 2000, Leblanc, 1995, Nogler, 1984, Noyes, 2005, Richards, 1996, Van Dijk et al., 1999). In order to assess the nature and the extent of variation in reproductive behavior in $38 \mathrm{C}$, an apomictic clone, we collected flow cytometrical, cytogenetical and molecular data within progenies obtained after pollination using $2 x$ maize progenitors. Although the majority of viable seedlings consisted of maternal individuals (similar DNA content and fingerprinting patterns, Figures $4 \mathrm{~A}$ and $5 \mathrm{~A}$ respectively), progeny also contained a mixture of non-maternal genotypes ( $9 \%$, Table 2; Figures 4 and $5)$. The prevailing triggering mechanism consisted of unreduced egg cell fertilization as shown by DNA content and fingerprinting analyses, both indicative of the addition of one maize haploid genome to that of $38 \mathrm{C}$ (Figures $4 \mathrm{~B}$ and $5 \mathrm{~A}$ ). The remaining nonmaternal progeny were infrequent $(<0.2 \%$ overall, Table 2$)$ and split into two categories regarding DNA content: (1) values twice that of the mother clone (Figure $4 \mathrm{C}$ ) resulting from parthenogenesis in egg cells derived from unreduced megaspores that underwent spontaneous chromosome doubling $(n=218 ; 2 n=76$, data not shown), and (2) a wide range of values significantly lower than that of the mother clone $(n=249$; Figures $4 \mathrm{D}$ to $4 \mathrm{H})$. 
A

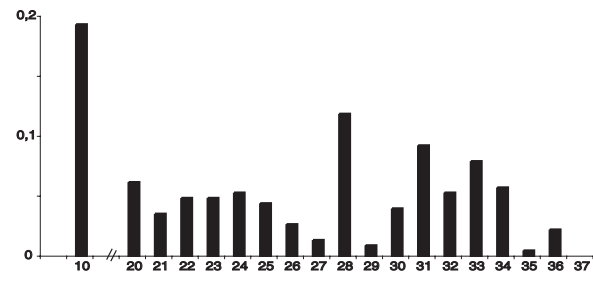

B
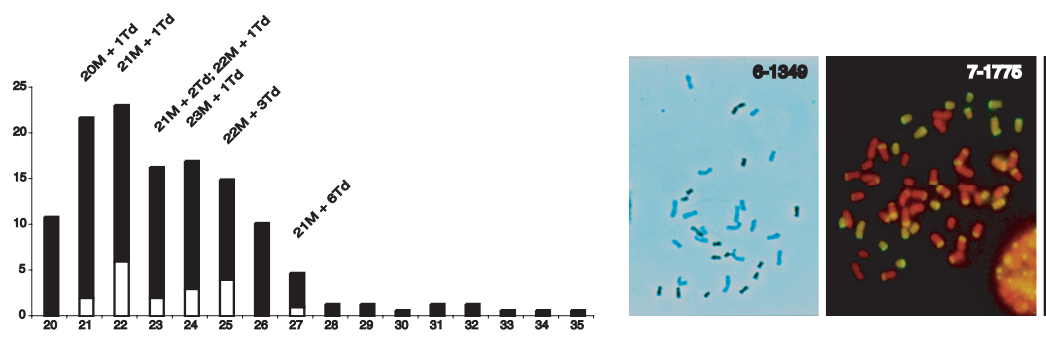

Fig. 6. Cytogenetical characterization of off type progeny obtained from apomictic 38C clones (A) and from highly facultative $\mathbf{2 n = 4 3}$ hybrids (B). (A) Chromosome number frequencies $(n=228)$ and chromosome painting in three archetypal derivatives with regard to their origin: 6-1393, sexually derived with $2 n=20 M+2 T d ; 6-1479$, asexually derived, but chromosomally imbalanced, with $2 n=31=17 M+14 T d$, and; 6-1415, a maize haploid. (B) Chromosome number distribution $(n=127)$ and chromosome painting in 6-1349 $(2 n=33=18 M+15 T d)$; in $7-1775$, one derivative of $6-1349$ through genomic accumulation $(2 n=43=28 M+15 T d)$, and; in $8-425$, a sexual offspring of $7-1775(2 n=23=22 M+1 T d)$. Sexual individuals that carried the DNA segment associated with diplospory distributed according to white bars and chromosome complements are indicated on top of corresponding bars. Chromosome painting was obtained using digoxygenin labeled Tripsacum DNA as a probe detected with either FITC or horseradish peoxidase as antidigoxygenin conjugate (Tripsacum chromosomes are yellow and dark blue respectively).

Figure $6 \mathrm{~A}$ displays chromosome numbers in 228 out of the 249 individuals of the latter class. Further cytogenetical and molecular characterization provided more comprehensive views for their nature and origin. A first set $(n=83)$ consisted of individuals derived sexually as molecular analyses revealed both segregating maternal markers and paternally inherited markers (Figure $5 \mathrm{~B})$. In addition, all plants determined for chromosomal complements $(n=62)$ combined a diploid maize genome with a few extra Tripsacum chromosomes (i.e., 6-1393, Figure 6A). The remaining individuals were categorized as follows: hybrids carrying aneuploid chromosome sets of maize, Tripsacum or both $(n=80$; $2 n=29$ to $2 n=36$, i.e., $6-1479$; Figure $6 A$ ) with fingerprint patterns indicating no paternal DNA (absence of karyogamy) and sporadic loss of maternal markers (Figure $5 C$ ); maize haploids $(n=40$; $2 n=10$, i.e., $6-1415$; Figure $6 \mathrm{~A}$ ) of maternal and paternal origin (data not shown), and; allodihaploid hybrids with $2 \mathrm{n}=10 \mathrm{M}+18 \mathrm{Td}$ $(n=25)$. All allodihaploids genotyped $(n=9)$ lacked paternal fragments indicating that they arose parthenogenetically from allodihaploid egg cells. However, we could not resolve unambiguously whether these eggs derived meiotically or ameiotically because of the lack of heterozygous maize markers detectable in $38 \mathrm{C}$ and of the small number of plants analyzed.

Finally, to test whether the viable seedlings we analyzed consisted in a biased sample for inferring reproductive behavior of $38 \mathrm{C}$ clones, we also estimated DNA contents in embryos dissected from defective kernels and in embryos that exhibited growth defects ( $\geq 250$ for each type; data not shown). In both cases, they arranged in a similar manner to that of viable seedlings.
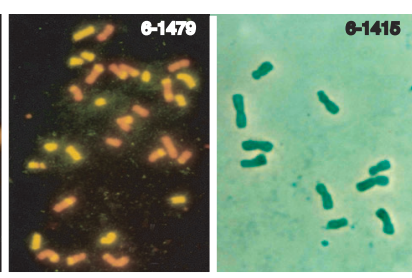

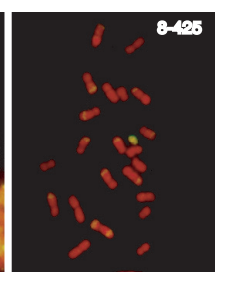

Here, as in many other apomictic species, $38 \mathrm{C}$ clones reproduced through facultative apomixis. Although genomic accumulation was predominant, genetic variation within progeny arose through a number of mechanisms. While incomplete nucleus restitution at meiosis I is a known side effect of diplosporous pathways (Nogler, 1984, Noyes, 2005, Richards, 1996) likely promoted by meiotic asynchrony between the maize and Tripsacum chromosomes in our materials (Grimanelli et al., 2003, Harlan et al., 1970), parthenogenesis in reduced gametes and spontaneous chromosome doubling did not occur at greater incidences than that observed in many sexual plant species (de Wet, 1979, Kimber and Riley, 1963) or in interspecific hybrids (Nasrallah et al., 2000, Soltis and Soltis, 1999).

\section{Transgenerational propagation of apomixis}

Understandably, the genetics of apomixis has been investigated mostly after transmission through reduced male gametes. However, recent progress toward the molecular deciphering of plant reproduction has revealed pivotal roles for female gametophytic factors during early seed development. Therefore, conceivably, maternal and paternal transmission might impact differently critical regulatory factors governing the apomictic phenotype. With regards to this, the collection of nonmaternal off-types we produced from clone $38 \mathrm{C}$ allowed us to examine maternal transmission of apomixis for a variety of modalities. In particular, we determined reproductive behaviors in non maternal derivatives with lower DNA content values than that of $38 \mathrm{C}$ based on progeny tests and Southern hybridizations using two diagnosis probes for diplospory, umc28 and cdo202 (Leblanc et al., 1995a). Data were in agreement for most hybrids analyzed $(n=106)$, except for three sexually derived individuals carrying the chromosome harboring the diplospory locus (Table 4). Considering the small number of incongruent individuals, we further wanted to

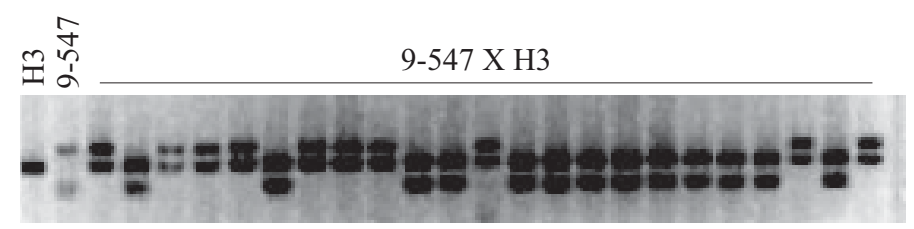

Fig. 7. Sexual behavior in 9-547, a maize-Tripsacum hybrid with

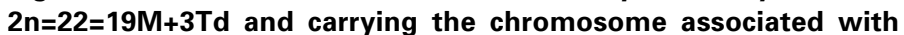
apomixis. Progeny were derived after crossing with a maize hybrid (H3) and amplicons were obatined using a SSR primer combination (bnlg339 locus). 
TABLE 4

REPRODUCTIVE MODE IN FERTILE, NON-MATERNAL DERIVATIVES OF 38C AS DIAGNOSED BY RFLP ANALYSES AND PROGENY TESTING USING AT LEAST 50 INDIVIDUALS

\begin{tabular}{lccc} 
Off type nature & N & RFLP & Pr. test \\
\hline Allodihaploids & 9 & + & $\mathrm{A}$ \\
Maize haploids & 25 & - & $\mathrm{S}$ \\
Asexually-derived aneuploids & 39 & + & $\mathrm{A}$ \\
Asexually-derived aneuploids & 2 & - & $\mathrm{S}$ \\
Sexually-derived addition lines & 28 & - & $\mathrm{S}$ \\
Sexually-derived addition lines & 3 & + & $\mathrm{S}$ \\
\hline
\end{tabular}

A: Apomictic. S: Sexual.

validate these observations using a larger population. To achieve this, the unusual reproductive behavior of derivatives of 6-1349, which reproduced through highly facultative apomixis (see next section for a detailed analysis), allowed the recovery of 166 individuals through sexuality. Southern hybridizations using umc28 identified 29 individuals that carried the DNA segment linked to diplospory, out of which 18 set seeds after crosses with diploid maize (see Figure 6B and next section for cytogenetical characterization). Lack of progeny in the remaining inviduals resulted from early developmental arrest, flowering failure, or seed defects. With regards to this, we observed a similar fertile-to-sterile ratio in the 137 inviduals diagnosed as sexuals (18:29 and 58:79, respectively), thus discarding strong deleterious effects induced by the apomixis-associated chromosome. Flow cytometrical and molecular data collected from a total of 1190 progenies indicated that all 18 fertile individuals selected as putative apomicts reproduced sexually (Figure 7). Although we cannot discard potential for functional apomixis in the sterile individuals, these results show that the segment defined by umc28 and cdo202 is not sufficient to confer apomixis by it-self. This suggests that apomixis might depend on critical Tripsacum genetic factors, unidentified in previous studies, and segregated away during meiosis. Alternatively, loss of apomixis in these materials might denote trans-acting chromosomal dosage effects modulating gene expression within the umc28/cdo202 segment (i.e., aneuploid syndrome).

\section{Assessment of the impact of genomic and chromosomal dosage variation on apomixis}

In natural populations, apomixis and polyploidy are usually associated. However, artificial ploidy variation in apomicts and related sexuals has produced ambiguous data, i.e., isolation of diploid or dihaploid apomicts (Bicknell, 1997, Dujardin and Hanna, 1986, Leblanc et al., 1996, Sharbel and Mitchell-Olds, 2001) vs. apomixis induction after ploidy rise in sexual Paspalum notatum (Quarin et al., 2001). Thus, whether polyploidy has a role in reshaping the sexual pathway towards apomixis remains to be elucidated. In higher organisms, many regulatory complexes for gene expression are dosage-dependent, mainly because of stoechiometric requirements among components (Birchler et al., 2001). As a result, changes in genome structure (aneuploidy, ploidy variation) often impact gene expression levels and, ultimately, phenotypes. Genomic accumulation and chromosome losses allowed the recovery of maize-Tripsacum lineages convenient for addressing the influence of dosage variation in tuning the balance between sexual and apomictic reproduction. First, we addressed the effects of aneuploidy through a chromosome deletion mapping approach by taking advantage of the chromosomally imbalanced apomicts previously determined for the mode of reproduction (Table 4). They were genotyped using a set of seventy-seven AFLP and twenty-seven SSR markers specifically amplified from the Tripsacum complement of 38C genome (Figure $8 \mathrm{~A}$ ). As shown in Figure 8B, most markers (92\%) failed to amplify the expected fragment in at least one individual. Despite small scale discrepancies in grass genome synteny (Devos, 2005, Goff et al., 2002), we assume that the marker set we used likely covered the entire Tripsacum genome. Therefore, chromosomal variation, except for that harboring the umc28/cdo202 region, had no significant effect on diplospory; although their developmental fate could vary across genotypes, most female gametes were unreduced. Secondly, we examined the impact of ploidy variation throughout genomic accumulation series derived from clones of $38 \mathrm{C}$ and chromosomally imbalanced derivatives that showed contrasted Tripsacum genome landscapes (Table 5). In order to limit the impact of allelic variation introduced through the male, plants were pollinated with $\mathrm{H} 3$, the male progenitor used in $38 \mathrm{C}$ pedigree. All progenies, but that obtained from hybrid 6-1349 $(2 n=33=18 M+15 T d$, Figure $6 B)$, showed a propensity for unreduced female gamete formation similar to that of their respective mother plant (Table 5). Therefore, although variations for parthenogenesis vs. fertilization in unreduced egg cells could be observed in some instances (a phenomenon noticed in most hybrid generations we generated), apomictic reproduction was prevalent in these materials. In derivatives of 6 1349 with $2 \mathrm{n}=43=28 \mathrm{M}+15 \mathrm{Td}$ (Figure 6B), DNA content estimates

TABLE 5

DNA-CONTENT-BASED PROGENY TESTS IN APOMICTIC CLONES WITH DIFFERENT CHROMOSOMAL COMPLEMENTS

\begin{tabular}{|c|c|c|c|c|c|c|c|}
\hline \multicolumn{5}{|c|}{ A - Apomictic clones } & \multicolumn{3}{|c|}{$B-2 n+n$ derivatives } \\
\hline Clone & $2 n$ & $\mathbf{N}$ & $\mathrm{Npr}$ & UR & $\mathbf{N}$ & $\mathrm{N}_{\mathrm{pr}}$ & UR \\
\hline $38 \mathrm{C}$ & 38 & nd & - & 0.99 & 27 & 726 & $0.93^{*}$ \\
\hline $6-1313$ & 36 & 4 & 310 & 1.00 & 5 & 41 & $0.96^{*}$ \\
\hline $6-1349$ & 33 & $>50$ & 5150 & 0.99 & 66 & 630 & 0.18 \\
\hline $6-1394$ & 34 & 12 & 1660 & 1.00 & 19 & 137 & $0.97^{*}$ \\
\hline $6-1439$ & 31 & 3 & 51 & 0.95 & 1 & 7 & $1.00^{\text {nd }}$ \\
\hline $6-1544$ & 35 & 9 & 1096 & 1.00 & 45 & 493 & $0.95^{*}$ \\
\hline $6-1580$ & 36 & 10 & 1112 & 1.00 & 25 & 278 & $0.97^{*}$ \\
\hline $6-1583$ & 36 & 15 & 1100 & 1.00 & 18 & 199 & $0.95^{*}$ \\
\hline
\end{tabular}

* indicates no significant difference to that observed in mother clone $(\alpha=0.05)$. nd: not determined 
revealed that only a small fraction originated from unreduced megagametophytes through either apomixis or genomic accumulation (18\%, Table 5B). The remainders arose sexually; they displayed a wide range of chromosome numbers and cytogenetical analyses indicated aneuploid maize chromosome complements (Figure 6B). Interestingly, 26 out of the 66 individuals with 43 chromosomes produced $100 \%$ sexual progeny. However, progeny size was generally low and it remained unclear whether reversion to sexuality was complete or partial. We further investigated possible male effects by pollinating clones of the seven hybrids originally selected (Table 5) using a set of 8 diverse maize CIMMYT lines (CML78, CML204, CML258, CML341, CML346, CML408, CML413 and CML416). Derivatives through genomic accumulation, including those derived from 6-1349, showed similar behavior to that of their original counterparts produced using H3 (data not shown), thus discarding that the phenomenon

\section{A}

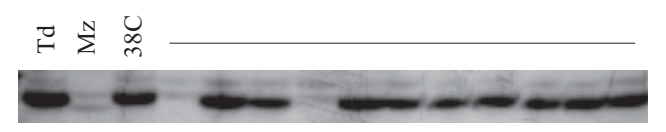

B

SSR Bin $\mathrm{m}$

$\begin{array}{ll}\text { phi97 } 1.01 \\ \text { bnlg1866 } & 1.03\end{array}$ bnlg400 1.09 bnlg1018 2.04 bnlg1225 2.06 bnlg1940 2.08 bnlg1523 3.03 dup5 3.04 bnlg2118 3.09 bnlg1162 4.03 bnlg1337 4.11 bnlg1006 5.00 bnlg2323 5.04 phi85 $\quad 5.07$ bnlg1867 6.01 umc28 6.07 cdo202 6.08 bnlg657 7.02 bnlg1161 7.04 phi116 7.06 bnlg1834 8.03 bnlg1782 8.05 phi022 9.03 bnlg1884 9.05 bnlg12 9.08 phi117 10.00 bnlg236 10.06 bnlg2190 10.06

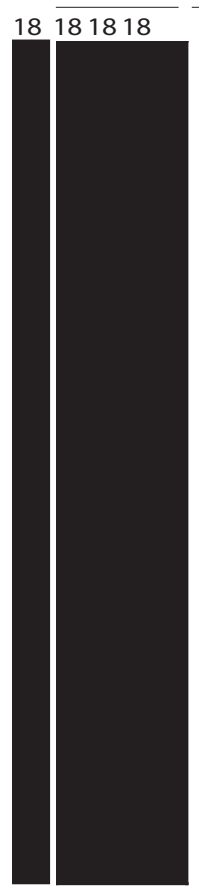
ph 000 chr. imb. pr.
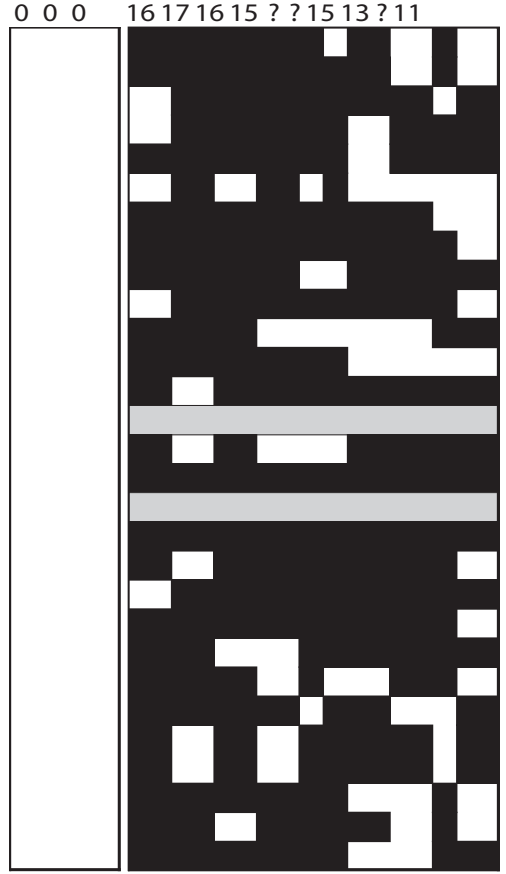

Fig. 8. Tripsacum genome landscapes in chromosomally imbalanced, asexual derivatives of maize-Tripsacum apomictic hybrid 38C. (A) Segregating pattern of one AFLP fragment specific to 65-1234, the Tripsacum dactyloides donnor. Mz: maize male progenitor. Td: 65-1234. 38C: $2 n=38$ maize-Tripsacum mother plant. (B) Tripsacum genomic contributions as determined by maize SSR markers detecting a fragment specific of the Tripsacum genome in $38 \mathrm{C}$ clones. Each column shows one individual, which Tripsacum chromosome number is indicated on top. m: maternal clone. chr. imb. pr.: chromosomally imbalanced progeny. mdh: maternal dihaploid $(2 n=28)$. ph: paternal haploid $(2 n=10)$. Gray areas: not determined. resulted from specific allelic interactions.

These findings indicate that neither chromosome depletion (except for that causing the removal of the segment homologous to maize $6 \mathrm{~L}$ ) nor maize genome addition can promote reversion towards sexuality, when endured by maize-Tripsacum chromosome complements proper for functional apomixis. Collectively, they suggest that apomixis responds little to genome plasticity, a behavior also documented recently in alloploid apomicts of the Boechera holboellii complex (Kantama et al., 2007). However, although the general mechanisms governing apomictic reproduction in maize-Tripsacum apomicts unlikely operate in a dosage dependent manner, the recurring reproductive shift between 61349 and its derivatives after genomic accumulation suggests that dosage dependency occurs to some extent and may account, at least partially, for variations in facultativeness commonly observed in apomictic species.

\section{Discussion}

Although the proposition for an epigenetic role have been put forward for the emergence of apomixis from the sexual pathway (regulation through epialleles, relaxation of genomic imprinting), its relevance remains largely unexplored (Grossniklaus et al., 2001, Koltunow and Grossniklaus, 2003, Ranganath, 2004). As discussed below, our observations lend support to epigenetics as a critical component in the biology of apomicts along two different lines: seed development and transgenerational propagation of apomixis. However, apomixis was expressed in our materials with no dependency for polyploidy nor for chromosomal variation, two mechanisms usually epigenetically regulated (Chen, 2007). This suggests that epigenetic effects associated with polyploidy unlikely participate in re-directing the sexual development towards apomixis, supporting the proposition that the usual association of polyploidy and apomixis can be regarded as an evolutionary adaptation, i.e. for balancing natural selection against apomictic genomes that accumulate deleterious mutations generation-wise (Mogie, 1992) and/or for preventing deleterious effects induced by apomictic DNA segments when transmitted through haploid gametes (Nogler, 1984).

\section{Two epigenetic mechanisms controlling sexual plant repro- duction act as barriers for apomictic seed development}

Development of both the embryo and the endosperm was affected in 38-chromosome apomictic clones. Deleterious dosage effects in endosperm development likely resulted from differential parental imprinting, a well described, but molecularly undetermined as yet, epigenetic phenomenon in seed plants. On the other hand, the epigenetic nature of embryo defects is less clear. The developmental defects we observed may denote genome wide effects resulting from the genetic makeup of this material as reported in newly formed allopolyploids (reviewed in Chen, 2007, Rapp and Wendel, 2005). In such hybrids, certain gene expression patterns vary suddenly and often reflect nonequivalent parental contributions to the transcriptome. Heritable changes, some of them of epigenetic nature (DNA methylation, chromatin structure), have been documented to explain the novel transcriptome observed in hybrids as well as its potential to persist over time (Adams et al., 2003, Kellogg, 2003). Since the genome of the maize-Tripsacum generations we described here likely has 
been subjected to allopolyploidization-induced effects, this material seems by nature unsuitable to investigate the impact of apomictic reproduction on DNA methylation patterns. On the other hand, although the polyploid origin of apomictic genomes in Tripsacum still needs clarification (Grimanelli et al., 1998) and in the light of recent data in resynthesized Brassica napus lines (Gaeta et al., 2007), we assume that possible epigenetic effects of polyploidization have been long stabilized. We show that Tripsacum apomictic progeny suffer from developmental defects and that methylation patterns within a single genomic clone (same or different generations) vary significantly. Aberrant genome methylation patterns have been shown to induce large pleiotropic effects on development in plants, including after cloning procedures (Cao and Jacobsen, 2002, Finnegan et al., 1996). All together, this suggests that apomictic progeny in Tripsacum carry an epigenetic load that arises from improper genome reprogramming of methylation states during apomixis. Therefore, in the light of the impact of the phenomenon in Tripsacum apomicts (Table 3), we believe that it explained most embryo developmental defects we recorded in maize-Tripsacum progeny.

Furthermore, the difference in viability between sexually and asexually derived offspring in Tripsacum likely results from the maintenance of critical epigenetic mechanisms acting during sexual plant reproduction. Whether the phenomenon is exclusive to our materials or expands to other apomictic systems remains to be investigated. Notably, short-circuiting of sexual programs in some apomicts allows to override epigenetic constraints for endosperm development (Grimanelli et al., 1997, Grossniklaus et al., 2001, Nogler, 1984), but data in aposporous Hieracium also support a role for epigenetics in apomictic embryo developmental defects (Koltunow et al., 2000). Clearly, further research will be required to determine the nature of the mechanisms responsible for both endosperm and embryo alterations in apomictic seeds.

\section{Restoration of sexuality upon transmission through fe- male sexual gametes}

Data obtained from asexual, chromosomally imbalanced, derivatives of $2 n=38$ apomictic hybrids strongly suggest that expression of apomixis in maize-Tripsacum hybrids relies upon one single Tripsacum chromosomal region: its removal caused reversion to sexuality and expression of the trait was independent of its chromosomal complement recipient as no response after genome or chromosomal dosage variation was observed. In view of these results, sexual reproduction in hybrids that derived sexually from apomictic mother plants and that carried the chromosomal segment associated with diplospory unlikely resulted from a missing chromosomal region critical for apomixis to function, but segregated away during meiosis. Likewise, chromosomal rearrangements were also discarded as we found only one rearranged chromosome among all the complements we determined cytogenetically ( $n=37$; data not shown). Apart from its chromosomal environment (that appeared neutral with regards to completion of the apomictic phenotype), another distinctive feature for the chromosome harboring the diplospory locus between sexually derived hybrids and chromosomally imbalanced hybrids stands in its transgenerational propagation, i.e. reduced, fertilized vs. unreduced, parthenogenetical female gametes, respectively. With regard to unreduced gametes, fertilization had little impact on the reproductive mode in the resulting derivatives as shown from data collected in genomic accumulation series. Finally, since our materials were fully male sterile, we could not perform reciprocal (sexual $X$ apomict) crosses to examine transmission through male gametes. However, it is worth mentioning that transmission through male Tripsacum gametes did not result in segregation distortion against apomixis (Leblanc et al., 1995a). Therefore, our data strongly suggest non-equivalency of the DNA region controlling apomixis when transmitted through reduced female gametes on one side and through unreduced female gametes and reduced male gametes on the other side, i. e. non functional vs. functional, respectively. These findings support the proposition for an epigenetic mechanism by which sexuality is restored when apomixis regulatory components are inherited through female reduced gametes. Such female germ line specific epigenetic repression has been reported in Drosophila as responsible for hybrid dysgenesis (Blumenstiel and Hartl, 2005) and telomeric Trans-Silencing Effect or TSE (Josse et al., 2007). Both phenomena result from maternal repression of transposable elements (TE) through a RNA silencing pathway while the paternal germ line transmits active TEs. In addition, TSE repressing mechanism is induced for TEs, or trans-genes, inserted into subtelomeric heterochromatin and shows variegation when silencing is not complete (Josse et al., 2007). Whether maternal repression of apomixis mechanistically relies on similar bases is unknown, but note that, in most cases investigated including Tripsacum, "apomixis DNA segments" consist of non-recombining chromosomal blocks. Finally, reports in Pennisetum indicate similar strong segregation distortion for the apospory-specific genomic region (AGSR) when inherited through sexual female gametes (Roche et al., 2001). Interestingly, the two DNA segments associated with apomixis, and cytogenetically best characterized to date, contain rearrangements of high repetitive sequences derived from transposable elements (Akiyama et al., 2004, Calderini et al., 2006). It is thus conceivable that the phenomenon has evolved in species reproducing through different apomictic pathways. A role for epigenetic repression of apomixis may be the maintenance of sexual reproduction within agamic complexes, a critical evolutionary force for population dynamics and adaptation.

Efforts towards the characterization of apomictic developments by molecular and cellular means have proven by far more complicated than thought in the $80-90$ s. Particularly, complexity comes from the diversity of phenotypes but also from the divergence between genetic analyses mostly pointing out a single dominant factor and either molecular mapping in apomicts or reproductive mutants analyses in model plants. In this report, we have provided evidence that apomictic seed likely suffer from an epigenetic load and that epigenetics influences, at least partially, inheritance of apomixis in maizeTripsacum hybrids. The limited knowledge for the molecular basis underlying apomictic phenotypes strongly hampers the assessment of the role of epigenetics in the trait. Nevertheless, although a small number of key events of the sexual pathway is believed to be sufficient for inducing apomixis from the sexual pathway (Bicknell and Koltunow, 2004, Grimanelli et al., 2001), the nature of the mechanisms required to sustain this switch might entail, and trigger, profound changes in the reproductive 
biology of sexual plants, therefore strongly limiting the efficiency of the conversion of sexual crop into apomicts.

\section{Materials and Methods}

\section{Plant material}

All Tripsacum and maize materials were obtained from CIMMYT Plant Genetic Resources Center (Table 1). The five apomictic Tripsacum dactyloides accessions used in this report (65-1234, 11-36, 61-664, 112$1327,112-1328$ ) have been previously characterized for the mode of reproduction and classified as diplosporous apomicts of the Antennaria type (Leblanc, 1995, Leblanc et al., 1995b).

The hybridization scheme we followed for the production of sexual and apomictic 38-chromosome maize-Tripsacum hybrids $(2 \mathrm{n}=20 \mathrm{M}+18 \mathrm{Td}, \mathrm{M}$ and Td indicate a maize and a Tripsacum origin, respectively) is detailed elsewhere comprehensively (Leblanc et al., 1996, Savidan, 2000) and summarized in Figure 1. The $T$. dactyloides donor used in the initial cross was $65-1234$, a tetraploid apomict with $2 n=72$. Note also that all maizeTripsacum hybrids used in this work derived from individuals of a single apomictic allodihaploid clone $(2 n=28=10 M+18 T d)$ and that 28 - and 38 chromosomes individuals are fully male sterile and were used as pistillate progenitors exclusively.

Occasional fertilization of unreduced female gametes in all dihaploid clones by a maize sperm cell (15\%; Leblanc et al., 1996) yielded 38chromosome hybrids. Male progenitors were as follows: $\mathrm{H} 1$ and $\mathrm{H} 3$, two maize $\mathrm{F} 1$ hybrids respectively derived from CML135 and CML139, and from CML135 and CML62, and individuals from 18 CIMMYT improved maize populations listed in Table 1. Subsequent backcrossing generations were derived using $\mathrm{H} 1, \mathrm{H} 3$ and CIMMYT Maize lines (CMLs, Table $1)$.

In most cases, Tripsacum and maize-Tripsacum progeny were grown from endosperm-filled kernels, but embryos dissected out of defective kernels were also rescued. Kernels were germinated in a dark growth chamber at $27^{\circ} \mathrm{C}$ on agar-solidified N6 medium (Chu et al., 1975) while dissected embryos were grown under similar conditions on N6 medium supplemented with $4 \%$ sucrose. Once selected, seedlings were acclimatized into Jiffy pots prior to transplanting into 20 inches pots.

\section{Determination of reproductive behavior in maize-Tripsacum hybrids}

Female-fertile hybrids were systematically progeny-tested. Evaluation of genetic hetero / homogeneity within progeny was primarily assessed by comparing DNA content estimates (collected through flow cytometry, see section below) in mother plants to that of offspring. In the backcrossing scheme we followed, similar DNA contents to that of the mother plant denoted apomixis whereas a significant difference indicated its failure. Typically, individuals resulting from the fertilization of an unreduced gamete showed an increase in DNA content while sexuality or haploidization caused a reduction (Figure 1). Further characterization was carried out for selected individuals by gathering cytogenetic and molecular data (see corresponding sections for experimental procedures). Molecular analyses consisted in detecting the chromosomal segment responsible for diplospory through RFLP analyses using umc28 and cdo202 clones (Leblanc et al., 1995a), and in genotyping progeny using maize Simple Sequence Repeat (SSR) and Amplified Fragment Length Polymorphism (Vos et al., 1995).

\section{Flow cytometric analyses}

DNA content values were estimated based on flow cytometric analyses (FCM) performed using a Partec CA-II device (PARTEC, Munster, Germany) and following a procedure adapted from Galbraith et al. (1983). Nuclei preparations consisted of filtrates ( $90 \mu \mathrm{m}$ mesh) of small pieces of tissues (e.g. leaf from young seedlings, dissected embryos, dissected endosperms) chopped using a razor blade into Galbraith's buffer containing $1 \mathrm{mg} / \mathrm{l}$ of 33342 Hoechst DNA dye (Sigma Aldricht, France).

Typically, fluorescence signals were collected from at least 2000 intact excited nuclei and they were plotted into intensity ( $x$ axis, 512 channels) $X$ nuclei counts ( $y$ axis) histograms. The flow cytometer was calibrated regularly by adjusting on channel 50 the fluorescence intensity of $2 \mathrm{C}$ peaks produced by leaf nuclei extracted from a diploid maize inbreed (CML62, CIMMYT line). Finally, the ratio of the mean intensity of the $2 \mathrm{C}$ peak $(\mathrm{CV}<5 \%)$ produced by the mother plant to that of each individual within progeny were used to assay the clonal nature of offspring, i.e. maternal clones produce a ratio of 1 while for off type individuals it deviates from 1.

\section{Chromosomal analyses}

Chromosome numbers were obtained from root tip preparations collected from young seedlings following Jewel and Islam-Faridi (1994). Chromosomal complements were determined using genomic in-situ hybridization as described by Islam-Faridi and Mujeeb-Kazi (1995).

\section{Molecular procedures}

Total genomic DNA extraction, Southern hybridizations and SSR detection were performed following standard procedures for maize.

Twenty-seven maize SSRs out of 235 were selected based on DNA amplification of $T$. dactyloides $65-1234$, of maize $(\mathrm{H} 1, \mathrm{H} 3)$, and of several individuals of a $2 n=38$ clone (data not shown) using the following criteria: detection of loci spread out in the maize genome and production of amplicons specific to the $T$. dactyloides genome in $2 \mathrm{n}=38$ maize-Tripsacum hybrids. Loci (name and bin) in the final selection were as follows: phi97 (1.01); bnlg1866 (1.03); bnlg400 (1.09); bnlg1018 (2.04); bnlg1225 (2.06); bnlg1940 (2.08); bnlg1523 (3.03); dup5 (3.04); bnlg2118 (3.09); bnlg1162 (4.03); bnlg1337 (4.11); bnlg1006 (5.00); bnlg2323 (5.04); phi85 (5.07); bnlg1867 (6.01); bngl657 (7.02); bnlg1161 (7.04); phi116 (7.06); bnlg1834 (8.03); bnlg1863 (8.04); bnlg1782 (8.05); phi022 (9.03); bnlg1884 (9.05); bnlgl128 (9.08); phi117 (10.00); bnlg236 (10.06); bnlg2190 (10.06) (for details see http:// www.maizegdb.org/probes).

Fingerprinting was performed using an AFLP procedure modified from Vos et al. (1995) that allowed chemiluminescent visualization of the amplified fragments. Ligation reactions were performed using DNA fragments produced by the $E c o R I$ and Msel restriction enzymes. For pre-selective amplifications, non-selective primers complementary to EcoR1 and Mse1 adapters were used (5'-GACTGCGTACCAATTC-3'. 5'-GATGAGTCCTGAGTAA-3', respectively). Selective amplifications were performed using identical primers with three additional nucleotides at the 3' ends (ACA for EcoR1 and CAA, CAT, CAC, CAG, CTC, CGG, and CTT for Mse1).

For assessing genome-wide DNA methylation, we followed the modified AFLP procedure of Cervera et al. (2002) to compare DNA fingerprints obtained from $\mathrm{EcoRl} / \mathrm{Msel}$ digests (methylation-insensitive polymorphisms) and from EcoRl/Hpall and EcoR1/Msp1 digests (methylation-sensitive polymorphisms). In order to avoid polymorphisms arising from differences in developmental stages (Finnegan et al., 1998), all DNA samples were obtained from the terminal leaf beneath the inflorescence.

\section{Histology}

Freshly collected kernels were fixed in FAA for 24 hours. Dehydratation, paraffin infiltration, sectioning $(10 \mu \mathrm{m})$, and staining (safranin / fast green) were made following standard procedures (Freeling and Walbot, 1994). Preparations were examined under a Zeiss Axiophot or Leitz Aristoplan light microscope.

\section{Acknowledgments}

This work was supported through a collaborative research agreement between IRD, CIMMYT, Groupe Limagrain, Syngenta Seed AG, and Pioneer Hi-Bred Int'l., Inc. The authors are grateful to Silverio Muñoz and Hugo Galicia (CIMMYT) for technical assistance with flow cytometry, and to José Galvez (CIMMYT Tlaltizápan Experimental 
Station) for field assistance. We thank Daphné Autran for helpful discussions.

\section{References}

ADAMS, K.L., CRONN, R., PERCIFIELD, R. and WENDEL, J.F. (2003). Genes duplicated by polyploidy show unequal contributions to the transcriptome and organ-specific reciprocal silencing. Proc. Natl. Acad. Sci. USA 100: 4649-4654.

AKIYAMA, Y., CONNER, J.A., GOEL, S., MORISHIGE, D.T., MULLET, J.E., HANNA, W.W. and OZIAS-AKINS, P. (2004). High-resolution physical mapping in Pennisetum squamulatum reveals extensive chromosomal heteromorphism of the genomic region associated with apomixis. Plant Physiol. 134: 1733-1741.

ALBERTINI, E., MARCONI, G., BARCACCIA, G., RAGGI, L. and FALCINELLI, M. (2004). Isolation of candidate genes for apomixis in Poa pratensis L. Plant Molecular Biology 56: 879-894.

ASKER, S. and JERLING, L. (1992). Apomixis in plants. CRC Press, Boca Raton, USA.

BABCOCK, E.L. and STEBBINS, G.L. (1938). The American species of Crepis: Their interrelationships and distribution as affected by polyploidy and apomixis. Carnegie Institution of Washington Publication 504: 1-119.

BANTIN, J., MATZK, F. and DRESSELHAUS, T. (2001). Tripsacum dactyloides (Poaceae): A natural model system to study parthenogenesis. Sexual Plant Reprod. 14: 219-226.

BERGQUIST, R.R. (1981). Transfer from Tripsacum dactyloides to corn of a major gene locus conditioning resistance to Puccinia sorghi. Phytopathology 71: 518520.

BERTHAUD, J., SAVIDAN, Y., BARRÉ, M. and LEBLANC, O. (1997). Maize, Tripsacum, and teosinte. B. Tripsacum. In Biodiversity in Trust, (ed. FUCILLO, D.SEARS, L. and STAPELTON, P.). University Press, Cambridge, pp. 227-235.

BICKNELL, R.A. (1997). Isolation of a diploid, apomictic plant of Hieracium aurantiacum. Sexual Plant Reprod. 10: 168-172.

BICKNELL, R.A. and KOLTUNOW, A.M. (2004). Understanding apomixis: Recent advances and remaining conundrums. Plant Cell 16 Suppl: S228-S245.

BIRCHLER, J.A., BHADRA, U., BHADRA, M.P. and AUGER, D.L. (2001). Dosagedependent gene regulation in multicellular eukaryotes: Implications for dosage compensation, aneuploid syndromes, and quantitative traits. Dev. Biol. 234: 275-288.

BLUMENSTIEL, J.P. and HARTL, D.L. (2005). Evidence for maternally transmitted small interfering RNA in the repression of transposition in Drosophila virilis. Proc. Natl. Acad. Sci. USA 102: 15965-15970.

BROWN, W.V. and EMERY, H.P. (1958). Apomixis in the Gramineae: Panicoideae. Am. J. Botany 45: 253-263.

CALDERINI, O., CHANG, S.B., DE JONG, H., BUSTI, A., PAOLOCCI, F., ARCIONI, S., DE VRIES, S.C., ABMA-HENKENS, M.H., LANKHORST, R.M., DONNISON, I.S. et al. (2006). Molecular cytogenetics and DNA sequence analysis of an apomixis-linked BAC in Paspalum simplex reveal a non pericentromere location and partial microcolinearity with rice. Theor. Appl. Genetics 112: 1179-1191.

CAO, X. and JACOBSEN, S.E. (2002). Locus-specific control of asymmetric and CpNpG methylation by the DRM and CMT3 methyltransferase genes. Proc. Natl. Acad. Sci. USA 99 Suppl 4: 16491-16498.

CARMAN, J.G. (1997). Asynchronous expression of duplicate genes in angiosperms may cause apomixis, bispory, tetraspory, and polyembryony. Biol. J. Linnean Soc. 61: 51-94.

CERVERA, M.T., RUIZ-GARCIA, L. and MARTINEZ-ZAPATER, J.M. (2002). Analysis of DNA methylation in Arabidopsis thaliana based on methylationsensitive AFLP markers. Molec. Genet. Genomics 268: 543-552.

CERVIGNI, G.D., PANIEGO, N., PESSINO, S., SELVA, J.P., DIAZ, M., SPANGENBERG, G. and ECHENIQUE, V. (2008). Gene expression in diplosporous and sexual Eragrostis curvula genotypes with differing ploidy levels. Plant Mol Biol 67: 11-23.

CHEN, Z.J. (2007). Genetic and epigenetic mechanisms for gene expression and phenotypic variation in plant polyploids. Annu. Rev. Plant Biol. 58: 377-406.

CHU, C.C., WANG, C.C., SUN, C.S., HSU, C., YIN, K.C., CHU, C.Y. and BI, F.Y. (1975). Establishment of an efficient medium for anther culture of rice, through comparative experiments on the nitrogen sources. Scientia Sinica 18: 659-666.
COOPER, D.C. (1951). Caryopsis development following matings between diploid and tetraploid strains of Zea mays. Am. J. Botany 38: 702-708.

DE WET, J.M. (1979). Origins of polyploids. Basic Life Sciences 13: 3-15.

DEAN, W., SANTOS, F., STOJKOVIC, M., ZAKHARTCHENKO, V., WALTER, J., WOLF, E. and REIK, W. (2001). Conservation of methylation reprogramming in mammalian development: Aberrant reprogramming in cloned embryos. Proc. Natl. Acad. Sci. USA 98: 13734-13738.

DEVOS, K.M. (2005). Updating the 'crop circle'. Curr. Opin. Plant Biol. 8: 155-62.

DUJARDIN, M. and HANNA, W.W. (1986). An apomictic polyhaploid obtained from a pearl millet $x$ Pennisetum squamulatum apomictic interspecific hybrid. Theor. Appl. Genet. 72: 33-36.

FARQUHARSON, L.I. (1955). Apomixis and polyembryony in Tripsacum dactyloides. Am. J. Botany 42: 737-743.

FINNEGAN, E.J., GENGER, R.K., PEACOCK, W.J. and DENNIS, E.S. (1998). DNA methylation in plants. Ann. Rev. Plant Physiol. Plant Molec. Biol. 49: 223-247.

FINNEGAN, E.J., PEACOCK, W.J. and DENNIS, E.S. (1996). Reduced DNA methylation in Arabidopsis thaliana results in abnormal plant development. Proc. Natl. Acad. Sci. USA 93: 8449-8454.

FREELING, M. and WALBOT, V. (1994). The Maize Handbook. Springer Verlag, New York.

GAETA, R.T., PIRES, J.C., INIGUEZ-LUY, F., LEON, E. and OSBORN, T.C. (2007). Genomic changes in resynthesized Brassica napus and their effect on gene expression and phenotype. Plant Cell 19: 3403-3417.

GALBRAITH, D.W., HARKINS, K.R., MADDOX, J.M., AYRES, N.M., SHARMA, D.P. and FIROOZABADY, E. (1983). Rapid flow cytometric analysis of the cell cycle in intact plant tissues. Science 220: 1049-1051.

GOFF, S.A., RICKE, D., LAN, T.H., PRESTING, G., WANG, R., DUNN, M., GLAZEBROOK, J., SESSIONS, A., OELLER, P., VARMA, H. et al. (2002). A draft sequence of the rice genome (Oryza sativa l. ssp. japonica). Science 296: 92-100.

GRIMANELLI, D., GARCIA, M., KASZAS, E., PEROTTI, E. and LEBLANC, O. (2003). Heterochronic expression of sexual reproductive programs during apomictic development in Tripsacum. Genetics 165: 1521-1531.

GRIMANELLI, D., HERNANDEZ, M., PEROTTI, E. and SAVIDAN, Y. (1997). Dosage effects in the endosperm of diplosporous apomictic Tripsacum (Poaceae). Sexual Plant Reprod. 10: 279-282.

GRIMANELLI, D., LEBLANC, O., ESPINOSA, E., PEROTTI, E., GONZALEZ DE LEON, D. and SAVIDAN, Y. (1998). Non-mendelian transmission of apomixis in maize-Tripsacum hybrids caused by a transmission ratio distortion. Heredity 80 (Pt 2): 40-47.

GRIMANELLI, D., LEBLANC, O., PEROTTI, E. and GROSSNIKLAUS, U. (2001). Developmental genetics of gametophytic apomixis. Trends Genet. 17: 597-604.

GROSSNIKLAUS, U., SPILLANE, C., PAGE, D.R. and KOHLER, C. (2001). Genomic imprinting and seed development: Endosperm formation with and without sex. Curr. Opin. Plant Biol. 4: 21-27.

GUSTAFSSON, A. (1946). Apomixis in higher plants. Part I. The mechanisms of apomixis. Lunds Univ. Årsskr. N. F. Avd 42: 1-66.

HAIR, J.B. (1956). Subsexual reproduction in Agropyron. Heredity 10: 129-160.

HANNA, W.W. and BASHAW, E.C. (1987). Apomixis: Its identification and use in plant breeding. Crop Science 27: 1136-1139.

HARLAN, J.R., DE WET, J.M.J., NAIK, S.M. and LAMBERT, R.J. (1970). Chromosome pairing within genomes in maize-Tripsacum hybrids. Science 167: 12471248.

HARLAN, J.R. and DEWET, J.M.J. (1977). Pathways of genetic transfer from Tripsacum to Zea mays. Proc. Natl. Acad. Sci. USA 74: 3494-3497.

ISLAM-FARIDI, M.N. and MUJEEB-KAZI, A. (1995). Visualization of Secale cereale DNA in wheat germplasm by in situ hybridization. Theor. Appl. Genetics 90: 595600.

JEWELL, D.C. and ISLAM-FARIDI, M.N. (1994). A technique for somatic chromosome preparation and c-banding of maize. In The Maize Handbook, (ed. FREELING, M. and WALBOT, V.). Spinger-Verlag, New York, pp. 484-492.

JOSSE, T., TEYSSET, L., TODESCHINI, A.L., SIDOR, C.M., ANXOLABEHERE, D. and RONSSERAY, S. (2007). Telomeric trans-silencing: An epigenetic repression combining RNA silencing and heterochromatin formation. PLoS Genetics 
3: $1633-1643$.

KAEPPLER, S.M., KAEPPLER, H.F. and RHEE, Y. (2000). Epigenetic aspects of somaclonal variation in plants. Plant Molec. Biol. 43: 179-188.

KANTAMA, L., SHARBEL, T.F., SCHRANZ, M.E., MITCHELL-OLDS, T., DE VRIES, S. and DE JONG, H. (2007). Diploid apomicts of the Boechera holboellii complex display large-scale chromosome substitutions and aberrant chromosomes. Proc. Natl. Acad. Sci. USA 104: 14026-14031.

KELLOGG, E.A. (2003). What happens to genes in duplicated genomes. Proc. Natl. Acad. Sci. USA 100: 4369-4371.

KIMBER, G. and RILEY, R. (1963). Haploid angiosperms. Botanical Rev. 29: 480531.

KINDIGER, B. and SOKOLOV, V. (1997). Progress in the development of apomictic maize. Trends Agronomy 1: 75-94.

KOLTUNOW, A.M. (1993). Apomixis: Embryo sacs and embryos formed without meiosis or fertilization in ovules. Plant Cell 5: 1425-1437.

KOLTUNOW, A.M. and GROSSNIKLAUS, U. (2003). Apomixis: A developmental perspective. Ann. Rev. Plant Biol. 54: 547-574.

KOLTUNOW, A.M., JOHNSON, S.D. and BICKNELL, R.A. (2000). Apomixis is not developmentally conserved in related, genetically characterized Hieracium plants of varying ploidy. Sexual Plant Reprod. 12: 253-266.

LEBLANC, O. (1995). Modes de reproduction dans le complexe agamique des Tripsacum, et analyse d'hybrides maïs-Tripsacum pour le transfert de l'apomixie chez le maïs. PhD thesis, Institut National Agronomique Paris-Grignon and Université Pierre et Marie Curie, Paris.

LEBLANC, O., GRIMANELLI, D., GONZALEZ DE LEON, D. and SAVIDAN, Y. (1995a). Detection of the apomictic mode of reproduction in maize-Tripsacum hybrids using maize RFLP markers. Theor. Appl. Genetics 90: 1198-1203.

LEBLANC, O., GRIMANELLI, D., ISLAM-FARIDI, N., BERTHAUD, J. and SAVIDAN, Y. (1996). Reproductive behavior in maize-Tripsacum polyhaploid plants: Implications for the transfer of apomixis into maize. J. Heredity 87: 108-111.

LEBLANC, O., PEEL, M.D., CARMAN, J.G. and SAVIDAN, Y. (1995b). Megasporogenesis and megagametogenesis in several Tripsacum species (Poaceae). Am. J. Botany 82: 57-63

LEBLANC, O., POINTE, C. and HERNANDEZ, M. (2002). Cell cycle progression during endosperm development in Zea mays depends on parental dosage effects. Plant J. 32: 1057-1066.

LIN, B.Y. (1984). Ploidy barrier to endosperm development in maize. Genetics 107: 103-115.

MANGELSDORF, P.C. and REEVES, R.G. (1931). Hybridization of maize, Tripsacum and Euchlaena. J. Heredity 22: 339-343.

MOGIE, M. (1992). The evolution of asexual reproduction in plants. Chapman \& Hall, London.

NASRALLAH, M.E., YOGEESWARAN, K., SNYDER, S. and NASRALLAH, J.B. (2000). Arabidopsis species hybrids in the study of species differences and evolution of amphiploidy in plants. Plant Physiol. 124: 1605-1614.

NISHIYAMA, I. and INOMATA, N. (1966). Embryological studies on cross-incompatibility between $2 x$ and $4 x$ in Brassica. Japan J. Genetics 41: 27-42.

NOGLER, G.A. (1984). Gametophytic apomixis. In Embryology of angiosperms, (ed. JOHRI, B. M.). Springer-Verlag, Berlin, pp. 475-518.

NOYES, R.D. (2005). Inheritance of apomeiosis (diplospory) in fleabanes (Erigeron, Asteraceae). Heredity 94: 193-198.

OZIAS-AKINS, P. (2006). Apomixis: Developmental characteristics and genetics. Crit. Rev. Plant Sci. 25: 199-214.

OZIAS-AKINS, P. and VAN DIJK, P.J. (2007). Mendelian genetics of apomixis in plants. Ann. Rev. Genetics 41: 509-537.

PETROV, D.F., BELOUSOVA, N.I., FOKINA, E.S., LAIKOVA, L.I., YATSENKO, R.M. and SOROKINA, T.P. (1984). Apomixis and its role in evolution and breeding. Oxonian Press, Ltd., New Dehli, India.

QUARIN, C.L., ESPINOZA, F., MARTINEZ, E.J., PESSINO, S. and BOVO, O.A. (2001). A rise in ploidy level induces the expression of apomixis in Paspalum notatum. Sexual Plant Reprod. 13: 243-249.

RANDOLPH, L.F. (1970). Variation among Tripsacum populations of Mexico and Guatemala. Brittonia 22: 305-337.

RANGANATH, R.M. (2004). Harnessing the developmental potential of nucellar cells: Barriers and opportunities. Trends Biotech. 22: 504-510.

RAPP, R.A. and WENDEL, J.F. (2005). Epigenetics and plant evolution. New Phytologist 168: 81-91.

REIK, W. and DEAN, W. (2001). DNA methylation and mammalian epigenetics. Electrophoresis 22: 2838-2843.

RICHARDS, A.J. (1996). Genetic variability in obligate apomicts of the genus Taraxacum. Folia Geobotanica et Phytotaxonomica 31: 405-414.

RIDEOUT, W.M., EGGAN, K. and JAENISCH, R. (2001). Nuclear cloning and epigenetic reprogramming of the genome. Science 293: 1093-1098.

ROCHE, D., CHEN, Z., HANNA, W. and OZIAS-AKINS, P. (2001). Non-mendelian transmission of an apospory-specific region in reciprocal crosses between sexual pearl millet (Pennisetum glaucum) and an apomictic F1 ( $P$. glaucum $x$. squamulatum). Sexual Plant Reprod. 13: 217-223.

SAVIDAN, Y. (2000). Apomixis: Genetics and breeding. In Plant breeding reviews, vol. 18 (ed. JANICK, J.). John Wiley \& Sons, Inc., pp. 13-86.

SHARBEL, T.F. and MITCHELL-OLDS, T. (2001). Recurrent polyploid origins and chloroplast phylogeography in the Arabis holboellii complex (Brassicaceae). Heredity 87: 59-68.

SOLTIS, D.E. and SOLTIS, P.S. (1999). Polyploidy: Recurrent formation and genome evolution. Trends Ecol. Evolution 14: 348-352.

SPILLANE, C., CURTIS, M.D. and GROSSNIKLAUS, U. (2004). Apomixis technology development-virgin births in farmers' fields? Nature Biotech. 22: 687-691.

TUCKER, M.R., ARAUJO, A.C., PAECH, N.A., HECHT, V., SCHMIDT, E.D., ROSSELL, J.B., DE VRIES, S.C. and KOLTUNOW, A.M. (2003). Sexual and apomictic reproduction in Hieracium subgenus pilosella are closely interrelated developmental pathways. Plant Cell 15: 1524-1537.

VAN DIJK, P.J., TAS, I.C., FALQUE, M. and BAKX-SCHOTMAN, T. (1999) Crosses between sexual and apomictic dandelions (Taraxacum). II. The break down of apomixis. Heredity 83: 715-721.

VOS, P., HOGERS, R., BLEEKER, M., REIJANS, M., VAN DE LEE, T., HORNES M., FRIJTERS, A., POT, J., PELEMAN, J., KUIPER, M. et al. (1995). AFLP: A new technique for DNA fingerprinting. Nucleic Acid Res. 23: 4407-4414. 


\section{Further Related Reading, published previously in the Int. J. Dev. Biol.}

See our Special Issue Plant Development edited by José Luis Micol and Miguel Angel Blázquez at:

http://www.ijdb.ehu.es/web/contents.php?vol=49\&issue=5-6

See our recent Special Issue Fertilization, in honor of David L. Garbers and edited by Paul M. Wassarman and Victor D. Vacquier at: http://www.ijdb.ehu.es/web/contents.php?vol=52\&issue=5-6

Self-incompatibility systems: barriers to self-fertilization in flowering plants Anne C. Rea and June B. Nasrallah

Int. J. Dev. Biol. (2008) 52: 627-636

From phenotypic to molecular polymorphisms involved in naturally occurring variation of plant development Carlos Alonso-Blanco, Belén Mendez-Vigo and Maarten Koornneef Int. J. Dev. Biol. (2005) 49: 717-732

Historical perspectives on plant developmental biology

Mieke Van Lijsebettens and Marc Van Montagu

Int. J. Dev. Biol. (2005) 49: 453-465

Gametophyte interaction and sexual reproduction: how plants make a zygote Leonor C. Boavida, Ana Maria Vieira, Jörg D. Becker and José A. Feijó Int. J. Dev. Biol. (2005) 49: 615-632

The making of gametes in higher plants

Leonor C. Boavida, Jörg D. Becker and José A. Feijó

Int. J. Dev. Biol. (2005) 49: 595-614

Control of reproduction by Polycomb Group complexes in animals and plants Anne-Elisabeth Guitton and Frederic Berger

Int. J. Dev. Biol. (2005) 49: 707-716

Seed maturation: developing an intrusive phase to accomplish a quiescent state Jesús Vicente-Carbajosa and Pilar Carbonero

Int. J. Dev. Biol. (2005) 49: 645-651

Flower and fruit development in Arabidopsis thaliana

Pedro Robles and Soraya Pelaz

Int. J. Dev. Biol. (2005) 49: 633-643

Young microspore-derived maize embryos show two domains with defined features also present in zygotic embryogenesis. Pilar S Testillano, Carmen Ramírez, Jezabel Domenech, Maria-José Coronado, Phillipe Vergne, Elisabeth Matthys-Rochon and María C Risueño

Int. J. Dev. Biol. (2002) 46: 1035-1047

Epigenetic reprogramming of the genome-from the germ line to the embryo and back again.

K L Arney, S Erhardt, R A Drewell and M A Surani

Int. J. Dev. Biol. (2001) 45: 533-540

Characterization of seed storage proteins and their synthesis during seed development in Olea europaea

W Wang, J De-Dios-Alche, AJ Castro, MI Rodriguez-Garcia

Int. J. Dev. Biol. (2001) 45: S63-S64

Mechanisms of the proliferation and differentiation of plant cells in cell culture systems.

H Fukuda, M Ito, M Sugiyama and A Komamine

Int. J. Dev. Biol. (1994) 38: 287-299

Molecular genetic approaches to plant development.

W Boerjan, B den Boer and $\mathrm{M}$ van Montagu

2006 ISI **Impact Factor $=3.577^{* *}$

Int. J. Dev. Biol. (1992) 36: 59-66

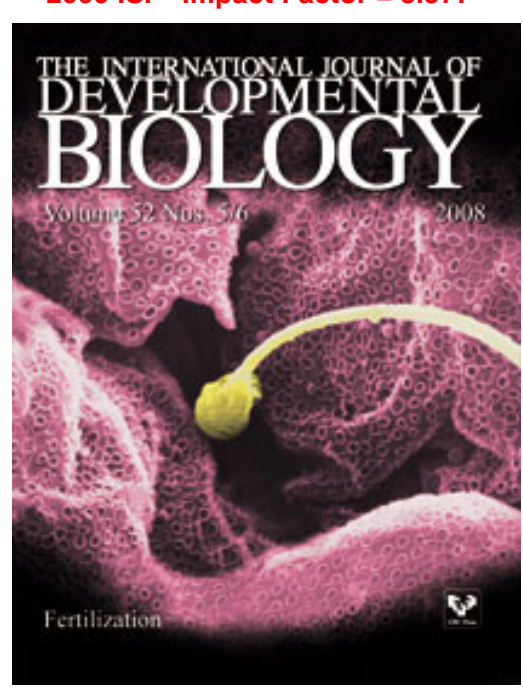

